\title{
THE AGEING POET AND DEATH ANXIETY: ART AS EXISTENTIAL THERAPY IN JOHN PEPPER CLARK'S “OF SLEEP AND OLD AGE”
}

\author{
Issa Omotosho Garuba \\ University of Ilorin, Ilorin, Nigeria
}

\begin{abstract}
Death anxiety refers to the human experience of death awareness and the accompanying inescapable disquiet it provokes. It is a phenomenon in human existence which has attracted substantial studies from existential and psychological perspectives. Noting that every individual experiences this anxiety at some point in life, largely as a result of the awareness of the inevitability of death, the manner and extent to which it is experienced vary from individuals. Meanwhile, existential reflections have described 'death acceptance' as the healthy route to lessening this angst. It therefore presupposes that acceptance of death (i.e. knowing that one is a being-towards-death and therefore embracing and acknowledging it) is existentially therapeutic. On this note, in studying J. P. Clark's Of Sleep and Old Age, artistic creativity is being constructed in the study as an existential therapy against death anxiety for the poetic persona. It is premised, on the one hand, on the poet's eloquent vision of the boredom of existence and the horror of death which characterize the atmosphere of the text. On the other, the poet's age has been considered as a factor-agent which has bestowed on him the capacity to be conscious of an imminent death, thereby accepting it via keen reflections in his art. The study adopts two theoretical models in existential studies: (1) Monika Ardelt's 'Wisdom', 'Religiosity' and 'Purpose in Life' and (2) John Sommers-Flanagan and Rita Sommers-Flanagan's model of 'Existential Therapy' to assess the sway and/or centrality of death anxiety to understanding the text.
\end{abstract}

Keywords: aging, death anxiety, existential therapy, John Pepper Clark, existentialism

\section{Article history:}

Received:10 August 2019;

Reviewed: 9 October 2019;

Revised: 16 October 2019;

Accepted: 20 December 2019;

Published: 30 December 2019

Copyright (C) 2019 Issa Omotosho Garuba

This open access article is published and distributed under a CC BY-NC 4.0 International License which permits non-commercial use, distribution, and reproduction in any medium, provided the original author and source are credited. Permissions beyond the scope of this license may be available at omotoshoissa@gmail.com. If you want to use the work commercially, you must first get the authors' permission.

Citation: Garuba, I. O. (2019). The Ageing Poet and Death Anxiety: Art as Existential Therapy in John Pepper Clark's "Of Sleep and Old Age". English Studies at NBU, 5(2), 268-283.

https://doi.org/10.33919/esnbu.19.2.5

Issa Omotosho Garuba holds a BA degree in English from Bayero University, Kano, Nigeria and a MA degree in English Literature from University of Lagos, Lagos, Nigeria. He is a doctoral candidate in the Department of English, Faculty of Arts, University of Ilorin, Ilorin, Nigeria. His current research focus is on American literature, specifically the relations between African American and Native American literatures. 
It has been established that one of the cardinal objectives of existentiallyinformed theorists and practitioners is anchored in a reminder of individuals of the temporality of our existence as human beings and of the inevitable inter-relationship between living and dying. This is significant in that, like our forebears, we can equally strive to "live lives that include death within our awareness of living" (Spinelli, 2008, p. xix). This further underlies the fact that one of the bases of existential thinking is indeed the "philosophy of life" (Choron, 1963, p. 222). Such a philosophical reflection on life is acknowledged to be practically impossible without reflection on the end of life, death in other words (Tomer \& Eliason, 2008, p. 8). The significance of such reflection on human existence is underscored thus:

Death illuminates the concrete existence of the individual, helps us understand what is limited, unique, problematic, or precious in his existence. On the other hand, our concepts of the nature of the individual, of concrete life, can illuminate the event of dying. Thus, meditations on life and death complement one another and may point both to strengths and to weaknesses in one another. In addition to being connected to an examination of human life and its meaning, or lack of meaning, philosophical reflection on death has engaged in an examination of Being, and the meaning of it. (Tomer \& Eliason, 2008, p. 8)

Although all these reflections may have been constructed and articulated from diverse perspectives, they all boiled down to what is regarded as the human psychological encounter with death, bearing in mind that death is "the only certainty in life. All living organisms die; there is no exception. However, human beings alone are burdened with the cognitive capacity to be aware of their own inevitable mortality and to fear what may come afterwards." (Wong, 2008, p. 65)

The above phenomenon of death awareness is perceived as a universal human experience and the accompanying inescapable mental uneasiness it provokes in every individual is described in several philosophical and psychological studies on death as death anxiety (Spinelli, 2008, p. xx). Regardless of age, state or status in life, from an existential standpoint, it is an anxiety which every human being experiences. Importantly, it is noteworthy that death anxiety "does not mean a life has not been welllived or that the individual does not love life" (Niemiec \& Schulenberg, 2004, p. 388). Rather, it is "rooted in the realization that life is inevitably moving towards death" (Cohn, 1997, p. 60). However, the manners as well as the extent to which individuals respond to this anxiety vary from one another. Thus, these variations in human 
response, in terms of manner and degree, have constituted substantial studies from existential, psychological and spiritual perspectives prominently regarded as death attitudes in human beings.

On the forgoing, bearing in mind that literary studies is indeed inseparable from existential, psychological and even spiritual studies, this study beams its search light on the manifestation of the phenomenon of death anxiety in the poetic persona, in a particular or specific form, in John Pepper Clark's poetry volume Of Sleep and Old Age. Specifically, the study adopts two theoretical models: (1) Ardelt's (2008) approach to death attitudes in aging adults, constructed on a triangular basis of 'Wisdom', 'Religiosity' and 'Purpose in Life'; and (2) Sommers-Flanagan \& Sommers-Flanagan's (2004) model of 'Existential Therapy'. The justification for the choice of the two theoretical perspectives is locatable in the poetic persona's status as an ageing individual vis-à-vis the conclusion of Ardelt (2008) in her study that:

Older adults tend to encounter death frequently and on a more personal level than do younger adults, and they often have already accepted the fact that their own death is more than a theoretical possibility.... Hence, some older adults might have to come to terms with the finitude of their life and might even look forward to a life after death and a reunion with their loved ones, while still being afraid of the unknown that death represents. (p. 151)

Indeed, the above attitudes, as part of the overall death anxiety in the poetic persona, are substantially traceable in the mood and tone of the entire collection of poems in the volume.

\section{Theoretical Framework}

In her study on death attitudes in ageing adults, the sociologist Monika Ardelt establishes that the phenomena - wisdom, religiosity and purpose in life - are three personality qualities from the perspectives of which the manifestation of death anxiety in this category of persons could be constructed. According to her, these personality qualities have been established as capable of alleviating death anxiety and negative attitudes towards death (2008, p. 140). In terms of scope, a number of 164 older hospice patients, nursing home residents, and community dwelling adults (of 58 to 98 years) from North Central Florida are sampled for the study (p. 140). The result of the study, therefore, shows a substantial positivity on the effects of wisdom, religiosity and purpose in life on death attitudes in older or aging adults. This is because, for such a 
people, as evident in the study, "fear of death and death avoidance are independent of their acceptance of death" (p. 151). In other words, it is revealed that 'fear of death' and 'death avoidance', as the two most prominent elements against which the manifestation of death anxiety can be measured in individuals, are less in aging adults in whom the above qualities are ascertainable, as compared to younger ones.

First, the definition of wisdom is constructed on three dimensions of personality characteristics. These are cognitive, reflective and affective. In conceiving these three parameters, it is posited that:

Wise people tend to look at phenomena and events from many different perspectives to overcome subjectivity and projections (reflective dimension) and to discover the true and deeper meaning of phenomena and events (cognitive dimension). This process tends to result in a reduction of self-centeredness, which is likely to lead to a better understanding of life, oneself, and others and, ultimately, to an increase in sympathy and compassion for others (affective). (p. 140)

Considering the above as the basis of wisdom, an individual in that state is said to possess the mental capacity to comprehend the fact that physical deterioration and death are inherent existential truths that can neither be ignored nor denied. Hence, it is of considerable expectation that wise people at this state in life remain relatively unafraid of death because they not only understand the true nature of existence, but have also "lived a meaningful life, and, therefore, are able to accept life as well as death." (p. 140)

The positive correlation of religiosity on death anxiety in the study is premised on the notion that "the main task of religion is to make sense of life and death" (p. 140). Hence, presumably, religious people tend to be "less afraid of death, because they often believe that they will be rewarded for their religious behavior in the afterlife" (p. 141). This implies that less or non-religious people are vulnerable to terror of death.

Similarly, the significance of purpose or meaning as the cardinal objectives upon which individuals could view their existence is highly emphasized. That is, individual adults who have lived their lives meaningfully and found purpose in it, unlike "older people whose lives do not appear to be worth living due to physical and/ or emotional strain", tend to "be less afraid of death and also more ready to let go" (p. 141).

Existential therapy, on the other hand, also has its basis in existential philosophy. It is described as a therapeutic activity that "plumbs the depths of an individual's most basic impulses in an effort to acknowledge, embrace, and integrate every bit of being 
and energy into the whole person" (Sommers-Flanagan \& Sommers-Flanagan, 2004, p. 144). Essentially, it helps individuals to be able to face and embrace the "ultimate concerns" of existence. Death, freedom, isolation and meaninglessness are the four conceptual phenomena described as the 'ultimate concerns' in existential therapy. The significance of these to existence is underscored thus:

These four concerns capture the nature of reality for existentialists. Everyone who lives is confronted with real demands and truths inherent in human existence. In turn, we are all free to choose our response to those demands and anxietyproducing truths. (Sommers-Flanagan \& Sommers-Flanagan, 2004, p. 146)

Against the background of the fact that all the four phenomena "produce anxiety" in every individual, therefore, in order to ensure healthy existence, it is maintained that they deserve to be "dealt with either directly or indirectly via defence mechanisms" (p. 146). Defence mechanisms, from an existentialist purview, are "not an elusive, automatic unconscious process, but a style or pattern of avoiding anxiety that can and should be brought to awareness" (p. 146). This thus presupposes the possibility of a therapeutic framework or frameworks with which these anxiety-producing abstractions could be dealt with in such a manner that it would translate into positive or healthy existence in an individual.

Meanwhile, on the forgoing, the phenomenon of death has been singled out, of the four, as being pertinent to this study. Citing the position of one of the prominent existentialists, Irving Yalom, Sommers-Flanagan \& Sommers-Flanagan (2004) assert that concerns about death are existentially therapeutic in two ways. First, it "whirs continuously beneath the membrane of life," and, thus, "exerts a vast influence upon experience and conducts" (p. 146). Secondly, it is conceived as "a primordial source of anxiety" and thus assumes "the main source of psychopathology" (p. 146), provided a significant level of comprehension is demonstrated towards it in order to embrace it as an ultimate truth of existence. This philosophical insight is reminiscent of Ernest Becker's assertion in the preface to his most powerful psycho-philosophical book The Denial of Death. According to him, “...the idea of death, the fear of it, haunts the human animal like nothing else; it is a mainspring of human activity - activity designed largely to avoid the fatality of death, to overcome it by denying in some way that it is final destiny of man" (1973, p. ix). All of these are indeed significant pointers to the fact that this anxiety is inevitable; that is, it is ascertainable in the activities of every individual. 
Hence, for the existentialists, concerns about death; that is, confronting, embracing and accepting it as an existential reality is therapeutic against its anxiety:

The purpose of facing death for existentialists is to experience life more deeply and fully. To face death is to motivate oneself to drink with great enthusiasm from the cup of life. Obviously, this is not a call for morbid preoccupation about life's end, but instead a call to shed external trappings and roles and to live in the now as an individual self with freedom of choice. (Becker, 1973, p. 147)

In the above, Ernest Becker is indeed unequivocal about the existentialists' preoccupation with end of life. As an existentially inescapable phenomenon, death is being portrayed as central in the overall human dealings with life. Hence, a resolve to confront it presupposes a move towards understanding life more deeply and fully as transient experience, which would consequently ease the inherent anxiety, if not obviated.

\section{Contextualising Aging in the Poet vis-à-vis his Writing: A Frame of Tradition and} Change

John Pepper Clark is one the most celebrated Nigerian poets. He is a poet, playwright and an essayist who rose to prominence especially in the 1960s and 70s concurrently with the likes of Wole Soyinka, Chinua Achebe, Christopher Okigbo, Gabriel Okara, among others, largely considered as the first generation of modern Nigerian writers. This period in Nigeria was significant to them in many respects. It was the post-independence era and their youthful age when they wrote with enormous vigour and social vision as writers who were highly sensitive to the socio-political travails and agonies of a nation that was experiencing post-independence troubles, culture conflict and the negative consequences of colonialism. Then, it is observable that explorations of personal issues in form of interior motives or individual psychology rarely got their way into the works of this set of writers. Rather, they were vigorously preoccupied with getting the nation on the right track by frowning at the pervasive social ills and setting proper ideological agenda for her in their writings. With specific reference to Clark, Egudu (1977) offers an overall overview of his poetry thus: "Greif, chaos, insecurity, and irredeemable loss are the hallmarks of the deftly woven fabric that is Clark's poetry. A tragic vision of life pervades his poems". (p. 25)

Despite the above, it is not surprising if the tradition is perceived to have somewhat metamorphosed into an exploration of the personal or foremost interiority of 
the poet as exemplified in his recent volumes written in his late 50s: Afterword (2002), Of Sleep and Old Age (2003) and Once Again A Child (2004). The poet's concern in these three volumes shifts significantly from his earlier works. This implies thus that these latter works assume another topical phase in the poet's artistic career. Here, the question of aging is largely being considered as the significant agent-factor for the ideological shift. Universally, the age bracket or period within which these works were written is an aging period in every individual, bearing in mind that it indeed falls within the age range contained in the scope of Ardelt's (2008) study. Hence, as apparently conveyed in the title of the volume under study Of Sleep and Old Age, Clark could be perceived as unconsciously exhibiting the so-called 'end of life' anticipations, typical of persons of his age, on a more personal rather than social level. Critically, this is conceivable as an aesthetic deviation from that which is identifiable with his earlier writing vision, occasioned by an unconscious shift in the frame of mind peculiar to individuals of such age range. By implication, thus, it could be hypothesized that, as an aging poet whose existence is construed as that which is currently fast winding down, the anxiety of the imminent death has unconsciously impacted this work, especially, as well as others cited above. Thus, the poet assumes, in this work, an existentialist-poet who seeks to confront death, as Becker (1973) posited, in a bid to "experience life more deeply and fully". (p. 47)

\section{Death Anxiety in Of Sleep and Old Age}

Of Sleep and Old Age is to a very great extent an exploration of personal human experience of the poet. The memory ranges from his family background, to his journey from childhood to old age and his career as a writer. In these intricately woven facets of experience, the question of living and dying are central. More specifically, like the existentialists, the poet reflects on the phenomenon of 'death' as the foremost decree on man which lies beneath his existence. The poet's eloquent vision of the boredom of existence and the horror of death observable in this text inform the existential reading of it which takes 'death anxiety' as central to the critical understanding of the text vis-àvis the psychology of the poet as a being in transition into old age.

Beginning with the very first poem "My father's house", the reader is taken through the poet's current mental state; the feeling of emptiness in him which his father's house, who has long passed on, is now symbolic of. This is perceived thus, giving 
his description of the house as a world, like a market place, once filled with people but which has now been horrifically deserted. This, for him, is terrifying because what he can now perceive at the moment is only his own reverberating heartbeat:

A courtyard,

Once like a market,

Night and day;

Now, not even an echo...

I hear my heart beat. (Clark, 2010, p. 317)

While in the above state, the memory of his loved ones, his long gone parents, as well as the atmosphere of those days when his father's house used to be peopled is grossly rekindled. This strong memory could be seen as a way of assuaging his mental desolation. This is vividly revealed in the two successive poems "A photograph" and "The last of the wives". In the former, the poet expresses how he stumbles on a photograph of his father amidst an ambience of desolation:

Then, one morning at home, feeling low, while

The people were out again in streets

And squares, looking for a man who would only

Lead them deeper into their wilderness,

I found in a cabinet, locked away

In a chamber, long out of use, among

Forgotten council papers, this picture

Of an old man, going back a hundred years. (p. 318)

In the above, in addition, the poet conveys a sense in which men are seen as beings wandering the earth's surface in search of life but, ironically, they are in search of what "would only lead them deeper into their wilderness", the state in which he has found himself following years of longing for existence. In the latter poem, the poet's loneliness is heightened such that the last of his father's wives, who is also still alive, is dragged into the picture as equally experiencing similar desolation, probably for him to feel some relief knowing that he is not alone in that state:

A woman now lives alone

In a compound where once she had

The company of other wives

As many as her husband

Had fingers.

With memories of an age

Long gone, she moves alone, like

A millipede, between her

Living rooms and her kitchen, 
At opposite ends of a courtyard,

Now the great fair has dispersed

And husband and all other wives

Have gone their separate ways

To homes in a place nobody knows. (pp. 322-323)

The significance of all of these is that, to him, that current state is entirely symbolic of "a call to heaven", as the title of the poem below bears, premised on the realisation that his late father as well others who have also passed on had once lived, but their souls have returned to the true owner, God who gave them in the first place:

God who has all

Wants the small life

He gave man;

God who is all

Still wants back all

He gave man and wife. (p. 327)

At the above point in time, as a result of that realisation of the temporality of human existence, the poet thus overtly demonstrates his awareness that his days are equally winding down. This is observable in his assertion that, in a world where his "days down the years make magic past masquerades", what he is left with are simply "debris of days" (p. 328). Against this backdrop, therefore, he realises a kind distance between him and his living mates, which is being gradually created, by his depleting days and the closeness or proximity to establishing a re-union with his loved ones who had once lived but have now been committed to the mother earth:

Those closest to me

Grow distant every day,

But those far away

I reach quite easily. (p. 329)

The above mental state is largely influenced by the poet's current state of growing old. This is in line with the final submission of Monika Ardelt in her study that "older adults tend to encounter death more frequently and on a more personal level than do younger adults, and that they often have already accepted the fact that their own death is more than a theoretical possibility" (p. 151). Indeed, the poet is perceived to be in that state of mind, i. e., to be amidst such an encounter with death and thus already having accepted its inevitability. Moreover, in this submission, it is evident that aging individuals are identifiable by two qualities of which the poet has equally demonstrated: awareness that death looms every day as well its inevitability. To this 
end, in the poem that follows, the poet is perceived to be indeed attributing his possession of these qualities to his age; that is, his age as the significant factor which has actually enhanced his being brought into that encounter with death:

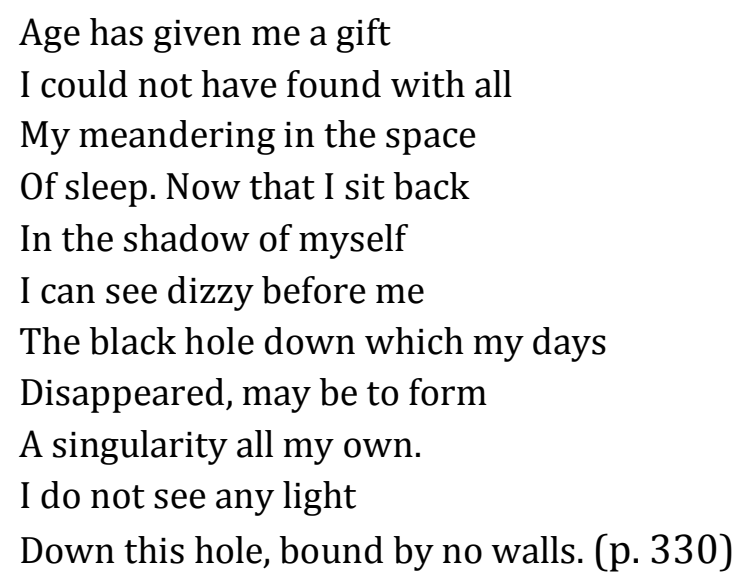

On the foregoing, it can be established that the poet's age is what has endowed him with the mental capacity to be aware of the realities and/or circumstances surrounding the phenomenon of death as an existential fact. In Ardelt's (2008) study, this is regarded as the personality characteristic of 'wisdom'. It is a state whereby the aging individual demonstrates adequate comprehension of the fact and inescapability of death, having been able to live a meaningful life. The poet exhibits this line of thought, specifically in the reflective and cognitive, by imagining the futility that characterise existence. Horribly, it is like drops of rain collected in a basket over a specific period of time:

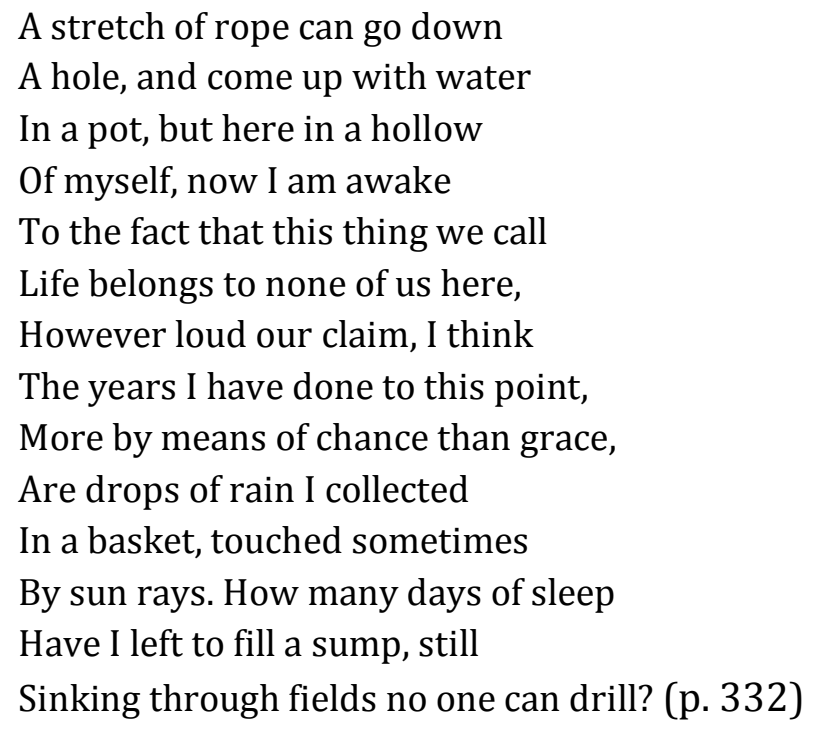

Indeed, the above shows the poet's cognition of 'existence' as a phenomenon which invariably translates to 'being-towards-death', to use Martin Heidegger's conception. Hence, obviously, he already has accepted it. To this end, he unconsciously 
pictures himself, in a dream-like state, as having joined those in the life beyond. This unconscious encounter with the dead ones is related momentarily thus:

The many faces I see again and

Again in my sleep, not counting

Family, friends and the thousands

I touched through work and play

I still do not know any to give

Them names, when crushed by their mass

I emerge out of breath from sleep (p. 339)

Upon regaining his consciousness, in the following stanza, the reader is made to understand that, beyond an imagination, what is revealed in his unconscious state earlier on amounts to a preview of the kind of company he is getting closer to eternally keeping, as his days unstoppably wind down:

These are no creations out of my art

But strange populations, moving on planes

I cannot summon out of space

For others to see and share their tongues.

Now, if this is all a preview

Of the company I am to keep

When I take my last sleep here on earth,

Then I want nothing of revelation. (p. 339)

In spite of the fact that the poet has, to a great extent, demonstrated cognition of the inevitability of death, the revelation that clouds his sleepy state above is still quite horrifying. Hence, he would want no further preview of such until the arrival of that crude moment when he will inevitably join his compatriots in the life beyond.

\section{Traversing the World of the Dead as a Therapeutic Measure against Death Anxiety}

There is no denying that living beings have the natural propensity to relate with the dead ones. This is a fact that psychological studies have equally corroborated, having located this interaction within the realm of the unconscious, especially in dreams. Sigmund Freud's study on dreams is a substantial pointer to this. Nevertheless, this does not disregard the fact that it would provoke some level of mystery when an individual is said to have had, or be having, an interaction with the dead. It would become more mysterious when such an individual demonstrates the ability to confidently relate the details of such engagement(s). The poetic persona in this study is indeed seen to be exhibiting this mental capability, as if he now visits and dines in the realm of the dead. 
The poet's ability to traverse the world of the dead in his unconscious (sleep state) is identifiable as a significant gift of age which has positioned the poet as a witness to the realities of the world beyond. This is a world between life and death that the poet is critically seen to inhabit at certain points in time. Sleep assumes his constant medium of journeying to afterlife, which indeed is significantly enhanced by his old age. To this end, the ultimate message he returns with is the imminent closure of his existence that his old age has inevitably condemned him to. This understanding largely signals the poet's acceptance of that very closure (death), even when it is ascertainable that an element of fear is still being entertained, considering his partial resistance to sleep at certain points as a way of avoiding being unconsciously thrown into the dream world wherein he constantly encounters death. The very poem that bears the title of the entire volume critically pictures the poet amidst this existential vicissitude:

Of sleep and old age, I believe, I may now speak as a witness Of truth. Not only is one state A function of the other, Sleep mimics so well the last act Of old all it wants is The very seal of closure. But while I can in all truth Resist the power and pleasure Of sleep, attendant upon My years in declension, old age, With unseen chains, leads me A bondsman to death, the master From whose beck and call it has No manumission. These twin Agents daily rock my bed. (p. 341)

At the above point in time, the manifestation of the therapeutic essence of the poet's concern about death in his artistic engagement is beginning to take shape. This is because the process of writing is perceived to have significantly aided him, in spite of the inherent terror, to be able to face and embrace death, as one of the ultimate concerns of his existence:

This life I lead I now find a load, As many I know also feel. Yet, just to think of letting go Fills me with fear of the void Into which we all vanish. (p. 347) 
Despite the above cognition of the circumstances surrounding existence and death, and the resolution to embrace and deal with them accordingly, it is not surprising that such an element of fear of death is still being entertained. It is only because he possesses, by virtue of his old age, the cognitive capacity to reflect into the past and see the void in the efforts of those who have passed on to avoid what was obviously and understandably unavoidable:

Old age truly is time

Top look back at events in the past,

Not to retrieve anything

For some archive, but I find,

Out of fear, the old try all

They can to fill the void

They see clearly in their front. (p. 348)

Amidst the entire concern, importantly to the poet, he craves for one more thing, which is equally of great concern to his reflection on and cognition of living and dying the existence of good critics that would demonstrate such keen, philosophical and psychological insights. That is, good literary critics in the contemporary period, like the class of which he knew, who would probably be able to read his work appropriately in the light of his direct confrontation with one of the ultimate concerns of existence. This is perceived as the construction of death in his art which ultimately assumes an existential therapy against death anxiety:

If it must be said again, Good critics of art are rare

To find, more so in these days

Of no law and order in the practice,

As there is none all over the land.

Of the rare class I knew well enough

To show my work, as it came,

Several now have gone to rest,

While others are just silent,

Or otherwise engaged in a world,

Driven mad by gain. (p. 352)

The rationale behind the poet's longing or craving for such critics above is locatable in the subsequent poem "A mirror image" wherein which the poet's concern is tantamount to an activity of subjecting his entire state of being, like a mirror image, to a form of artistic re-evaluation for others (critics) to read via diverse critical lenses:

When I look at myself in a mirror,

Made special by some craft, 
I see my right becomes my left,

And my left, my right. The image

Then is not as others see me,

Dressed up as I may be for a party,

Which may also be stepping out

Of myself. Yet I have it in my mind

This firm belief I look truly myself,

When I see myself in my mirror,

Knowing well the face I see

Is only a shade I show the world. (p. 357)

Seeing and constructing himself critically as only a mere shade being shown to the world through his artistic mirror, he paradoxically weighs his life (i.e., the grand sum of what he could regard as his achievement) as rather illusory because all was given to him only to be taken back by the giver at any time against his will. He thus queries the essence of his so called existence when even only a minutest part of it could be, by chance, left to immortalize him:

All I have collected every day

To myself amount to grand sum

I like to call my life, the one thing

In life I do not own, knowing now

It was given to be taken back

Any day against my will; and I

Also know that, when all has been said

And done, only a part of that

I have collected in my life will,

With some small luck, be left to my name. (p. 383)

At this point, the above assumes a novel knowledge of existential truth to the poet. Therefore, as a literary artist, this is being confronted with and embraced in his art. This is what is conceived in this study as being the medium through which the poet seeks to purge himself of the underlying anxiety of death. Hence, he makes his terminal testament which greatly signifies his ultimate acceptance of the ultimate existential concern. Critically, thus, these final words from the poet which are translatable to his acceptance of death, as embodied in the last poem of the volume "My last testament", are conceived as indeed constituting a therapy for the poet against the terror and anxiety of death upon his perception and/or cognition of its inevitability and imminence:

This is to my family:

Do not take me to a mortuary,

Do not take me to a church,

Whether I die in or out of the town, 
But take me home to my own, and

To lines and tunes, tested on the waves

Of time, let me lie in my place

On the Kiagbodo River.

If Moslems do it in a day,

You certainly can do it in three,

Avoiding blood and waste;

And whatever you do after,

My three daughters and my son

By the only wife I have,

Do not fight over anything

I may be pleased to leave behind. (p. 385)

Truly, the foregoing greatly re-echoes the poet's cognition of his existence as ultimately a being-towards-death and, therefore, acceptance of this crude reality. This is especially evident in his explicit message to his family emphasizing the need to eschew wastefulness in terms of time and material resources during his funeral while he would be, above all, pleased if no feud is entertained among them over whatever property he leaves behind. All of these are enormous pointers to the poet's preparedness to confront or embrace that very last moment on earth upon its arrival.

\section{Conclusion}

The study has attempted to construct aging as the impulsive context of John Pepper Clark's confrontation with death or the process of dying in his poetry volume of Sleep and Old Age. Premised on the notion that death exists simultaneously with life, and is thus capable of exerting anxiety on an individual (Sommers-Flanagan \& SommersFlanagan, 2004), the aging poet is critically seen to be preoccupied in his art with a therapeutic measure to absolve himself of this anxiety in the form of a strong will to confront, embrace and deal with it in order to be able to accept it as an ultimate truth of existence. In view of this, for the aging poet or persona, art significantly serves the purpose of existential therapy. This is because it is within this realm of existence that he is perceived to have been able to purge or divest himself of the inherent anxiety by subjecting his existence to a critical frame describable as 'to be, and, therefore, is not to be'. It is similar to what is called the process of meaning-making in death studies which involves "the construction of meaning through language, culture, story, goal-striving, and personal development". (Niemiec \& Schulenberg, 2011, p. 390) 
Furthermore, it is also deducible from the study that Sommers-Flanagan's \& Sommers-Flanagan's (2004) conception of existential therapy indeed corroborates the findings of Ardelt's (2008) study which, by implication, constructs wisdom, religion, and purpose in life as having the propensity to impact positively on the attitudes of aging individuals towards the phenomenon of death. In this way, thus, reading the text within the two theoretical contexts has yielded a specific, interwoven premise on which the two theoretical expositions on death attitudes adopted in the study can be further justified.

\section{References}

Ardelt, M. (2008). Wisdom, Religiosity, Purpose in Life, and Death Attitudes in Aging Adults. In Tomer, A., Eliason, G. T. \& Wong, P. T. P. (Eds.) Existential and Spiritual Issues in Death Attitudes, (pp. 139-158). New York: Taylor \& Francis Group.

Becker, E. (1973). The Denial of Death. New York: The Free Press.

Clark, J. P. (2010). Full Tide: Collected Poems. Ibadan: Mosuro Publishers.

Chon, H. W. (1997). Existential Thought and Therapeutic Practice. New York: Sage.

Choron, J. (1963). Death and Western Thought. New York: Macmillan.

Egudu, R. (1977). Four Modern West African Poets. Lagos: Nok Publishers.

Niemiec, R. M. \& Schulenberg, S. E. (2011). Understanding Death Attitudes: The Integration of Movies, Positive Psychology, and Meaning Management. Death Studies, 35(5), 387-407. https://doi.org/10.1080/07481187.2010.544517

Sommers-Flanagan, J. \& Sommers-Flanagan, R. (2004). Counselling and Psychotherapy Theories in Context and Practice: Skills, Strategies, and Techniques. New Jersey: John Wiley \& Sons.

Spinelli, E. (2008). Foreword. In Tomer, A., Eliason, G. T. \& Wong, P. T. P. (Eds.) Existential and Spiritual Issues in Death Attitudes, (pp. xxix-xx). New York: Taylor \& Francis Group.

Tomer, A. \& Eliason, G.T. (2008). Existentialism and Death Anxiety. In Tomer, A., Eliason, G. T. \& Wong, P. T. P. (Eds.) Existential and Spiritual Issues in Death Attitudes, (pp. 7-37). New York: Taylor \& Francis Group.

Wong, P. T. P. (2008). Meaning Management Theory and Death Acceptance. In Tomer, A., Eliason, G. T. \& Wong, P. T. P. (Eds.) Existential and Spiritual Issues in Death Attitudes, (pp. 65-87). New York: Taylor \& Francis Group. 